\title{
Leaving violent relationships and avoiding homelessness - providing a choice for women and their children
}

\author{
Jan Breckenridge ${ }^{\mathrm{A}, \mathrm{B}, \mathrm{D}}$ and Jane Mulroney ${ }^{\mathrm{C}}$

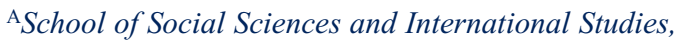 \\ University of New South Wales \\ ${ }^{\mathrm{B}}$ Centre for Gender-Related Violence Studies, University of \\ New South Wales \\ ${ }^{\mathrm{C}}$ Australian Domestic and Family Violence Clearinghouse, \\ University of New South Wales \\ ${ }^{\mathrm{D} C o r r e s p o n d i n g ~ a u t h o r . ~ E m a i l: ~ j . b r e c k e n r i d g e @ u n s w . e d u . a u ~}$
}

\begin{abstract}
The report Staying Home/Leaving Violence describes a research study that explores how women, leaving a relationship where they experience domestic violence, can remain safely in their own homes with their children, with the violent offender being removed. In this qualitative study, 29 women were interviewed about their experiences of leaving a violent relationship. Of these 29 women, nine remained in their own home. This article describes the factors that enabled these nine women to remain in their homes and comments on the policy and practice implications for health workers.
\end{abstract}

The literature frequently assumes that leaving a domestic violence relationship requires that women and their children leave the family home. Certainly for many women, leaving their home as a way of leaving the violent relationship is the only option that ensures their safety. This option, however, can be problematic for some women. For a proportion, despite leaving both their relationship and their home, the violence continues ${ }^{1}$ or can escalate. ${ }^{2}$ Moreover, there are other consequences of leaving the family home, which may result in some women feeling that they have no choice but to remain in, or subsequently return to, a violent relationship. ${ }^{3}$ These include homelessness or ongoing housing difficulties, ${ }^{4,5}$ poverty, ${ }^{6}$ lack of ongoing police assistance to prevent postseparation violence 7,8 and ongoing difficulties with child contact arrangements and Family Court matters. ${ }^{9}$ It would seem that notwithstanding the limited successes of public policy initiatives, such as refuges and supported accommodation schemes, ${ }^{10}$ and criminal justice responses, such as apprehended violence orders (AVO), ${ }^{8,11}$ many women experience a reduced quality of life and sense of well-being after leaving the family home - although they are safer in many instances.

More recently, researchers and practitioners have begun to explore other options that may potentially increase a woman's safety without necessitating her leaving her home. Edwards ${ }^{12}$ study on the use of exclusion provisions in AVOs in NSW is indicative of a move to eliminate violence from the home by excluding the offender rather than the victim(s). This genre of inquiry reorients research questions away from barriers to women leaving their home and towards the possibility of women and their children remaining in the family home while the offender leaves or is assisted to find alternative accommodation. The report Staying Home/Leaving Violence comprehensively extends this theme in its presentation of a study conducted by the Australian Domestic and Family Violence Clearinghouse in partnership with the Centre for Gender-Related Violence Studies, UNSW. ${ }^{13}$ Staying Home/Leaving Violence explicitly focused on how women leaving violent relationships could potentially remain safely in their homes with their children, with the violent partner being removed.

This article presents a summary of aspects of this research and outlines implications for health policy and practice.

\section{The Staying Home/Leaving Violence study}

The Staying Home/Leaving Violence study is a retrospective qualitative research study that was conducted between October 2002 and December 2003. The geographic areas in NSW chosen for inclusion in the study were the Area Health Services of South Eastern Sydney, Western Sydney and Southern. Fourteen domestic violence services from these areas facilitated the participation of 29 women in face-to-face, in-depth interviews that primarily focused on their experiences of leaving violent relationships. Approval to conduct the research was provided by the Human Research Ethics Committee of the University of NSW.

All participants had left a relationship involving domestic violence and were living in safe situations at the time of interview. Fourteen of the women were from Anglo- 
Australian backgrounds, nine from culturally and linguistically diverse backgrounds, five women were Aboriginal and one woman was Maori. The participants were aged between 22 and 63 years (approximately two thirds of the women were aged between 22-39 years). Twenty-seven of the women had a total of 78 children between them, with ages ranging from two months to adulthood. At the time of interview, most women could be described as being of low socio-economic status. Nineteen women were in receipt of a Centrelink pension, benefit or allowance, although many of the women combined this with part-time work or TAFE studies. The 10 remaining participants were in either part or full time paid employment.

Twenty women had long-term (longer than five years) relationships with their violent partner and twenty-two participants had sought some legal protection or had contact with the criminal justice system. On leaving their violent relationship, nine remained in their home and 20 left. The focus of this article is the experiences of the group of nine women who remained. A discussion of the reasons that the other participants left the family home is available in the project report.

Interviews were taped and transcribed in all but four situations, in which detailed notes were taken during the interviews. The data collected were thematically analysed for the participant's experiences, ideas and beliefs about leaving the violent relationship. To ensure that the women's stories are integral to this article, the participant's exact words will be presented in italics.

\section{Factors underpinning women's choices to remain in the home}

Three factors were identified that enabled these women to remain in their homes. An additional factor, related to the characteristics of the perpetrator, was critical in some, but not all, cases.

\section{The women had a strong attachment to their home and felt they had a right to remain.}

In direct contrast to many of the participants who left home, these women spoke about their attachment to their home; one stated, 'this was my home forever'. Another echoed this sentiment stating, 'you've got your whole life here'. The practicalities of leaving were also of concern as suggested by one woman: 'I really need that security... 'cause I didn't want to be running around lost'. Another women's attachment to her home was more pragmatic and related to the needs of her physically disabled son. Her home had been modified and was located near the special school he was attending. To leave the home would jeopardise his well-being.

Closely related to the women's attachment to the home was their sense that they had a right to remain there. In the words of one, 'you make it your home and he shouldn't be able to force me out'. Other women commented on the fairness of women being forced to leave. For example, 'I don't believe that a woman has to be chucked out of her own home and she's the one that's the victim, she's the victim'. Other participants believed that they had been responsible for paying the mortgage or rent and that, therefore, they had paid for their home, 'every hard-working cent'.

\section{The violent partner was removed by the authorities (police and/or courts) or went voluntarily because he had other housing options}

Five partners left voluntarily and four were removed by the police and/or by order of the court (family and local). Where the perpetrator left voluntarily, the woman had been able to 'stand her ground' and force them to leave often due to her having some leverage such as knowledge of other criminal or antisocial activities, or by demanding that the man repay bond and any other money owed. Men left more readily if they had somewhere or someone else to go to. One woman describes the offender as being relieved not to have to pay her back the bond and leaving their home voluntarily to live in a boarding house where, 'he's just as happy as Larry'.

Equally, the significance of police removing the violent partner combined with a Telephone Interim Order (with an exclusion condition), and then an AVO (with exclusion condition) cannot be over-emphasised. This process ensures that the violent partner is not only removed from the premises initially but is also kept away from the home. One woman believed that her experience with a proactive officer had been a turning point. Police had attended her home many times and on this final occasion had taken action by arresting her violent partner, taking him away and charging him with assault. Generally the women in this study identified police response as a critical factor in deciding to leave the violence.

While the women had concerns for their safety, they were not overwhelmed by fear, and had developed a range of safety measures to help them feel safer at home

While at least six of the nine women experienced extreme levels of physical violence from their partner, all nine believed that they had made choices or utilised strategies that contributed to an increased sense of empowerment and greater safety. Women identified the importance of (i) using existing criminal justice provisions and personnel, 'taking out an AVO has made me feel secure'; (ii) making the house more secure and using available technology, 'I really think that it's essential to have a phone on... and also change the locks on your house'; and (iii) reporting breaches of AVOs and dealing with the offender away from the home for child contact visits, as successful safety strategies. 
The importance of developing these strategies is also that they allowed the women to no longer feel paralysed with fear and responsible for the violence. Moreover one participant articulated that developing safety strategies facilitated a shift in the dynamics of power and control, 'I had moved beyond fear'. It also appeared that the women's emotional attachment to their partner changed significantly. They no longer respected or wanted to be in a relationship with their partner. As one woman stated, 'he spends most of his time at the pub so he may as well live there'. While further research is required, it did appear that the women's growing empowerment coincided with a deepening dysfunction in their partner's lives. Of the nine ex-partners, only one did not have gambling and/or drug and alcohol problems. ${ }^{13}$

The perpetrator was intimidated by the police and courts and/or felt a duty to abide by legal rulings

An unanticipated finding was the partner's attitude and behaviour towards the law. Many of the 20 women who left their home described how their partners did not respect the police or the courts, disregarded AVOs and were not scared of going to gaol. However, for some but not all of the nine women who remained in their home, the perpetrator was intimidated by the police and the courts and felt a duty to abide by legal rulings. One participant encapsulated the fear this select group of offenders feel in relation to the criminal justice system, describing that her violent partner 'went to jelly' in court and 'couldn't speak' when confronted by police and the magistrate. The reaction of these offenders underscores both the importance and potential effectiveness of a coordinated criminal justice response.

\section{Enhancing practice}

The following strategies were identified from the findings as pertinent for health and welfare workers to consider in order for them to better assist women and their children to remain safely in their homes:

(1) removal of the violent partner from the home,

(2) keeping the violent partner out of the home over time,

(3) provision of immediate and longer-term safety for the woman and her children (including both physical and psychological well being) and

(4) longer-term support for the woman and children, and prevention of further violence.

The study also recommended several changes in relevant NSW government agencies with the aim of promoting a 'whole of government' policy and practice framework. ${ }^{13}$ To further test practices that enabled women to stay in their homes on ending a violent relationship, it was envisaged that pilot service delivery models would be established in the three Area Health Services that participated in the original study. Two pilots have been established in the South Eastern Sydney Area Health Service and Southern Area
Health Service. Several other regional areas have plans to establish similar models in their community. The evaluation of the pilot studies will provide information to the government and community sector on innovative responses to domestic violence.

\section{Policy and practice implications for health workers}

The recognition of domestic violence as a serious global public health problem by the World Health Organization's report on violence ${ }^{14}$ underscores the importance of this issue for health workers. This is consistent with findings in the literature that domestic violence can result in post traumatic stress disorder for victims and children, ${ }^{15}$ and other health issues such as depression, anxiety and phobias, suicide attempts, substance abuse, chronic pain syndromes, psychosomatic disorders, physical injury, gastrointestinal disorders, irritable bowel syndrome and a variety of reproductive consequences. ${ }^{16}$ Children may suffer several adverse health consequences; for example, child abuse is more likely to occur in families experiencing domestic violence. ${ }^{17}$

The effects of homelessness or diminished life circumstances after leaving the family home compound the possible psychological, social and emotional after-effects of living with domestic violence. Health workers who see women and children at the time of crisis for medical services or for later follow-up in counselling and support services need to be aware that a lack of housing options contributes to a longer term negative impact on women's efforts to establish a safe, secure and appropriate family environment. The findings provide different practice strategies and postseparation choices, which health workers could incorporate into their existing practice and which may enhance the quality of life for women and children who leave a domestic violence relationship.

\section{Conclusion}

Enabling women and children to remain in their home also brings several wider social, economic and health benefits to the whole community, such as reducing women's homelessness and potential poverty; keeping children out of the child protection system and with their non-violent parent; minimising the trauma in women and children's lives and holding the perpetrator accountable for the violence. Seen from this perspective, supporting women and their children to remain in their homes is likely to be a cost-effective strategy, but more importantly it is a socially responsible solution that seeks to prioritise victims' needs and improve the health and well-being of women and children.

\section{References}

1. Health Outcomes International. Improving women's safety, partnerships against domestic violence. Canberra: Office of the Status of Women, Department of the Prime Minister and Cabinet, 2004 
2. Mouzos J, Segrave M. Homicide in Australia: 2002-2003 national homicide monitoring program (NHMP) annual report. Canberra: Australian Institute of Criminology, 2004.

3. Anderson MA, Gillig PM, Sitaker M, McCloskey K, Malloy K, Grigsby N. Why doesn't she just leave? A descriptive study of victim reported impediments to her safety. J Fam Violence 2003; 18(3): 151-5. doi:10.1023/A:1023564404773

4. Casey S. Snakes and ladders: women's pathways into and out of homelessness. In: Eardley T, Bradbury B, editors. Competing visions: refereed proceedings of the National Social Policy Conference; 2001 July 4-6. Sydney: Social Policy Research Centre, UNSW, 2002. pp. 75-90.

5. AIHW (Australian Institute of Health and Welfare). Homeless people in SAAP: SAAP National Data Collection annual report 2003-2004 Australia. Canberra: AIHW (SAAP NDCA report series 9), 2005.

6. Baker CK, Cook SL, Norris FH. Domestic violence and housing problems: a contextual analysis of women's helpseeking, received informal support, and formal system response. Violence Against Women 2003; 9(7): 754-83. doi:10.1177/1077801203009007002

7. Johnson J, Luna Y, Stein J. Victim protection orders and the stake in conformity thesis. J Fam Violence 2003; 18(6): $317-23$.

8. Hall J. A new family law system - are we prepared? A report from a DVIRC forum. Domestic Violence \& Incest Resource Centre Newsletter 2005; 2: 19-21.

9. Kaye M, Stubbs J, Tolmie J. Negotiating child residence and contact arrangements against a background of domestic violence. Queensland: Griffith University Families, Law and Social Policy Research Unit, 2003.

10. Marcolin S. Female SAAP clients and children escaping domestic and family violence. Canberra: Australian Institute of Health and Welfare, 2005.

11. Coulter ML, Chez RA. Domestic violence victims support mandatory reporting: for others. J Fam Violence 1997; 12 : 349-56. doi:10.1023/A:1022857022792

12. Edwards R, editor. Beyond the divide: 3rd National Homelessness Conference; 2003 April 6-8; Brisbane, Australia. Canberra, ACT: Australian Federation of Homelessness Organisations (AFHO), 2003.

13. Edwards R. Staying home/leaving violence: promoting choices for women leaving abusive partners. Sydney: Australian Domestic and Family Violence Clearinghouse, 2004.

14. Krug EG, Dahlberg LL, Mercy JA, Zwi AB, Lozano R. World report on violence and health. Geneva: World Health Organization, 2002.

15. Mertin P, Mohr PB. Incidence and correlates of posttrauma symptoms in children from backgrounds of domestic violence. Violence Vict 2002; 17(5): 555-67. doi:10.1891/vivi.17.5.555.33712

16. King M. Roads to healing: therapeutic jurisprudence, domestic violence and restraining order applications. Brief 2003; 30(7): $14-5$.

17. Laing L, Bobic N. Literature review: economic costs of domestic violence. Sydney: Australian Domestic and Family Violence Clearinghouse, 2002. 